\title{
EXTENSION ACTIVITIES PROVIDED TO RICE FARMERS IN RAISING THE AWARENESS FOR COMPOST MANUFACTURE IN AL-DIWANIYAH PROVINCE
}

\author{
A. T. H. Al-Salhi
}

Lecturer

Dept. of Agri. Exten. and Techn.Trans. , Coll. of Agric. Engin. Sci, University of Baghdad ahmedthwaini@coagri.uobaghdad.edu.iq

\section{ABSTRACT}

This study was aimed to determine extension activities provided to rice farmers in raising the awareness for compost manufacture in Al-Diwaniyah province and investigate the level of awareness of rice farmers in the field of compost manufacturing, as well as the problems facing farmers when manufacturing compost, mythology a questionnaire design to collect data from rice farmers during the $\mathbf{2 0 1 8}$. The research society consisted of the agricultural departments of the directorate of Agriculture in Al Diwaniyah province. A random sample was taken from rice farmers related to the agricultural departments in the Directorate of Agriculture with their (632) farmers, The results of this study inculcated that the level of awareness for the farmers in the manufacture of compost, The average tends to weak in their awareness, The role of the agricultural extension has also just through extension seminars, which is considered one of the most extension activities were used to rice farmers of compost manufacturing, In addition, there is an absence of workers in the field of composting of rice residues, It could be to pay adequate attention to the rice crop as a strategic crop through the utilization of its waste and the elimination of environmental pollution that occurs as a result of burning those waste.

Key Word: agricultural extension , extension Seminars, field day

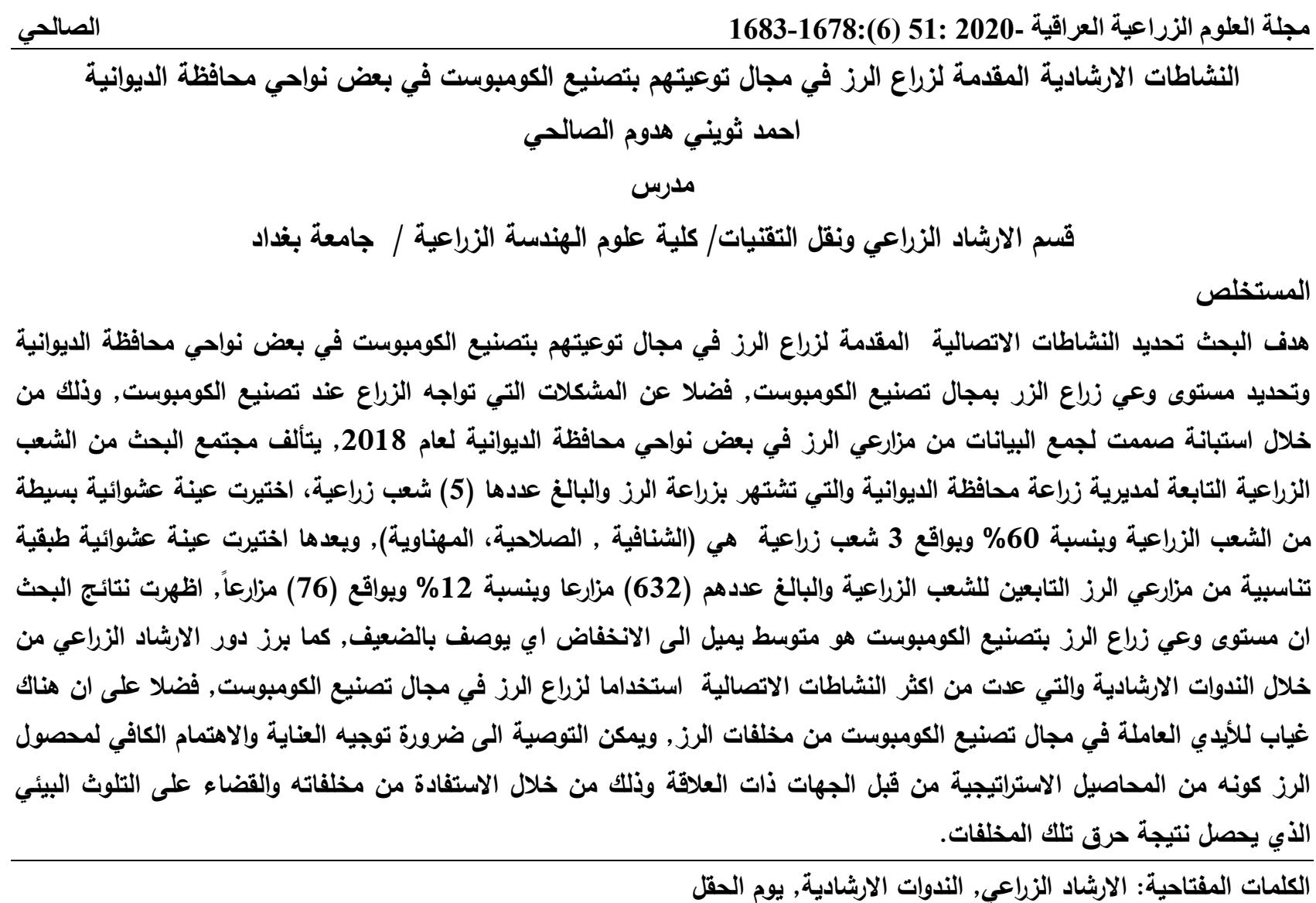




\section{INTRODUCTION}

Iraq like other countries in the Middle East, suffers from the risk of environmental pollution to the rural or urban by affecting their products or when consumed. This risk is rice by increasing the quantity and quality of agricultural waste and the absence of environmental awareness in the population as well as the lack of the necessary means to control environmental pollution (23). The issue of environmental pollution the protection and preservation of the environment from all types of pollution has become one of the most important issues of the world (17), which represents a major challenge to development plans as a result of the unconscious behaviour human with the environment (15).This in turn affects those development programs that lead to economic and human losses (6). While the policies of all countries, including Iraq to the reduce these losses and the optima economic use of the agricultural waste instead of burning it, which leads to increased environmental pollution (22). It has been shown that the burning of agricultural waste leads to the loss of significant economic resources with the continued diseases resulting from them as well as increased dependence on chemical fertilizers and thus continue the cycle of environmental pollution (20). Therefore,could take care to follow the appropriate principles in protecting the environment from pollution (7). Utilizing agricultural waste instead of burning it, which leads to increased environmental pollution (22). Waste energy potential, which is considered untapped (18), and recycled into useful materials such as compost that are adding to the soil in order to improve its physical and chemical properties and thus improve productivity and achieve economic returns for farmers (9). Agricultural waste is a wealth that must be preserved and exploited in the production of composts that protect the soil from degradation, as well as being a source of clean energy (16). From this review agricultural waste incorrectly lead to damage to the components of the environment and despite the existence of modern technologies that help and facilitate the utilization of agricultural waste, There was also an urgent need for the presence of extension and communication devices to facilitate the flow of information, knowledge and skills related to how to benefit from these wastes, including rice residues (10). Many studies indicated the low knowledge of farmers in dealing with agricultural waste (16). This could be due to the weakness of the extension apparatus in providing extension services( 13) As well as a lack of extension activities educating rice farmers about the importance of agricultural wastes and how to benefit from them. This study was aimed to know the extension activities provided to rice farmers in raising the awareness of compost manufacture in some districts of Al-Diwaniyah province, specifically, the research indicates the following questions:

1- What are the Extension activities provided to rice farmers in raising the awareness of compost manufacture in some districts of AlDiwaniyah province?

2- What is the level of awareness of rice farmers to manufacture compost in some districts of Al-Diwaniyah ?

3. What problems do rice farmers facing when composting?

\section{The aims of study}

1- To determine the Extension activities provided to rice farmers in raising the awareness of compost manufacture in some districts of Al-Diwaniyah province.

2 - To determine the level of awareness of rice farmers in the field of compost manufacturing in some districts of Al-Diwaniyah.

3 - To know the most important problems facing rice farmers.

\section{MATERIALS AND METHODS}

The research is one of survey studies that fall within the descriptive approach (21), which describes the phenomena accurately in order to reach the facts related to the role of agricultural extension in raising the awareness of rice farmers to manufacture compost in some districts of Al-Diwaniyah province from the point of view of rice farmers. This approach is appropriate for the study of such aspects.

\section{Study area}

The Al-Diwaniyah province was chosen as a research area, as it is one of the governorates that are famous for rice cultivation, during 2018. 


\section{Study community and samples}

The study community include :

A -The agricultural department of the Directorate of Agriculture in Al Diwaniyah province, which is famous for rice cultivation (Shafiya, Ghamas, Muhannawiyah, Salahiya, Shanafiya)

B- Rice farmers belonging to the agricultural department (3646) frames as shows in Table 1.

\section{Table 1. Distribution of the number of} farmers in the agricultural departments of Al-Diwaniyah province

\begin{tabular}{|ll|}
\hline $\begin{array}{l}\text { Agricultural } \\
\text { departments }\end{array}$ & $\begin{array}{l}\text { The number } \\
\text { of farmers }\end{array}$ \\
\hline AlShnaifiya & 119 \\
AlShaafa'is & 1456 \\
ghmas & 1270 \\
Alsalahia & 143 \\
AlMahnawiya & 370 \\
Average & 3646 \\
\hline
\end{tabular}

\section{Study samples}

1- A simple random samples were taken from the agricultural departments of the Directorate of Agriculture in Al Diwaniyah province, and by $60 \%$ and by 3 agricultural departments (Shnafip, validity, Mahnawiya).

2 - The proportionate stratified random sample was selected from the rice farmers belonging to the agricultural departments the Agriculture in Al Diwaniyah province, which numbered (632) farmers, by $12 \%$ and by (76) farmers distributed among the agricultural departments, and their preparation shows in Table 2.

Table 2. Distribution of the sample of farmers to the agricultural departments included in the research

\begin{tabular}{|lll|}
\hline $\begin{array}{l}\text { Agricultural } \\
\text { departments }\end{array}$ & $\begin{array}{c}\text { The number of } \\
\text { farmers }\end{array}$ & $\begin{array}{c}\text { The number } \\
\text { of sample }\end{array}$ \\
\hline AlShnaifiya & 119 & 14 \\
& 143 & 17 \\
Alsalahia & $\mathbf{3 7 0}$ & 45 \\
AlMahnawiya & $\mathbf{6 3 2}$ & $\mathbf{7 6}$ \\
Average & $\mathbf{2 3 2}$ & \\
\hline
\end{tabular}

Preparing data collection questionnaire (Study Tool)

The research tool is defined as the means that the data output of the study population (2).In order to achieve the research aim of determining the level of awareness of rice farmers in the field of compost manufacturing in some districts of Al-Diwaniyah
Governorate, a special questionnaire was designed based on several methods, including the opinions of experts and specialists. Studies, researches and articles related to the compost manufacturing, the international information network. The questionnaire is a basic tool and one of the good means by which the data required to achieve research purposes can be obtained (19).It is presented in the form of a grope of questions that the respondents are asked to answer (8). In order to obtain the necessary data about the research, the questionnaire consisted of three parts:

The first part of the questionnaire contained a scale to determine the extension activities provided by the agricultural extension for rice farmers in the compost manufacturing, and the development of a three-step scale consisting of (Much, sometimes, Scarcely), respectively. The second part contains a measure to determine the level of awareness of rice farmers in the compost manufacturing in some districts of Al-Diwaniyah governorate and includes seven processes under which compost manufacturing is conducted to: (Preparation of land and plant residues added, stirring of compost mix, water spray rate, compost time, method of manufacture and Signs of maturity), the farmers were given a score for each paragraph in the case of the correct answer is given 1 and in the case of the wrong answer is given 0 , and after obtaining data classify these scores to three levels (low, medium, high) and The number of respondents, percentages and the average level of awareness for each level were calculated.. While the third part of the questionnaire contained the most important problems facing rice farmers in the field of compost manufacturing and the development of a three-phase scale consisting of (large, medium, low) respectively.

\section{Validity of the scale}

The validity of the test means its ability to measure what it was designed for (21), which is the degree to which the scale can achieve its objectives (12). In order to identify the validity of the questionnaire was presented to a group of experts and specialists in the field of agricultural extension, soil and water resources to measure the Face Validity and content validity. After the introduction of their 
observations were made some adjustments to the questionnaire, which is one of the means to identify the validity of the research tool and the extent of representation of the scale components for aspects of the measured filed (1).

\section{Stability of scale}

The pre-test was conducted on a reconnaissance sample (excluded from the research sample) consisting of 10 growers. To determine the stability of scale level of extension activities, stability was measured statistically by analyzing the pre-test data by using the Alpha-Cronbach's method for these measures $(0.86,0.82,0.78)$ for each level of farmers' awareness of compost manufacturing and extension activities provided by the agriculture extension. The problems facing rice farmers are compost manufacturing, respectively. Data were collected during the month of September 2018 through a personal interview of rice farmers belonging to the agricultural departments covered by the research, as it is one of the most common means of obtaining information, instead of writing answers give the interviewer information verbally and write down the researcher answers (4) A personal interview is defined as "a method of collecting information directly from others through personal contact and is often used as a complement to other methods of data collection," (3). After the data was collected, it was reviewed, checked, classified, tabulated, and statistical methods were used to process this data through statistical analysis program (SPSS), percentage, The Weighted Mean (8),weight percentage (5), Alpha-Kronbach equation. (12).

\section{RESULTS AND DISCUSSION}

\section{The first aim}

The indicative the communications activities by the Directorate of Agriculture in Al Diwaniyah province and agricultural departments in the areas covered by the research for rice farmers in the field of compost manufacturing have been identified as in Table. 3

Table 3.The Extension activities provided to rice farmers for 2018

\begin{tabular}{|ccccccc|}
\hline Extension activities & \multicolumn{2}{c}{ Much } & \multicolumn{2}{c}{ Sometimes } & \multicolumn{2}{c|}{ Scarcely } \\
& number & \% & number & $\%$ & number & $\%$ \\
\hline Field or home visits & 21 & $\mathbf{2 7 . 6}$ & $\mathbf{4 3}$ & $\mathbf{5 6 . 6}$ & $\mathbf{1 2}$ & $\mathbf{1 5 . 8}$ \\
the extension seminars & $\mathbf{5 9}$ & 77.6 & $\mathbf{5}$ & $\mathbf{6 . 6}$ & $\mathbf{1 2}$ & $\mathbf{1 5 . 8}$ \\
extension meeting & $\mathbf{1 8}$ & $\mathbf{2 3 . 7}$ & $\mathbf{4 0}$ & $\mathbf{5 2 . 6}$ & $\mathbf{1 8}$ & $\mathbf{2 3 . 7}$ \\
Field Day & $\mathbf{2 4}$ & $\mathbf{3 1 . 6}$ & $\mathbf{3 2}$ & $\mathbf{4 2 . 1}$ & $\mathbf{2 0}$ & $\mathbf{2 6 . 3}$ \\
lecture & $\mathbf{2 4}$ & $\mathbf{3 1 . 6}$ & $\mathbf{4 0}$ & $\mathbf{5 2 . 6}$ & $\mathbf{1 2}$ & $\mathbf{1 5 . 8}$ \\
Extension Bulletins & $\mathbf{2 6}$ & $\mathbf{3 4 . 2}$ & $\mathbf{3 6}$ & $\mathbf{4 7 . 4}$ & $\mathbf{1 4}$ & $\mathbf{1 8 . 4}$ \\
Television or radio programs & $\mathbf{1 8}$ & $\mathbf{2 3 . 7}$ & $\mathbf{4 1}$ & $\mathbf{5 3 . 9}$ & $\mathbf{1 7}$ & $\mathbf{2 2 . 4}$ \\
Social networking & $\mathbf{2 0}$ & $\mathbf{2 6 . 3}$ & $\mathbf{3 8}$ & $\mathbf{5 0}$ & $\mathbf{1 8}$ & $\mathbf{2 3 . 7}$ \\
\hline
\end{tabular}

The Table above shows, that the extension seminars came the first rank of the activities by agricultural extension to rice farmers in the field of compost manufacturing and by a percentage $(77.6 \%)$ and the number of 59 farmers and The reason may be due to the knowledge of all respondents about the importance of the extension seminars held by the Agricultural Extension and its direct impact on the respondents. While the television and radio programs ranked last in terms of the level of activities by the Agricultural Extension, which received a percentage of $(23.7 \%)$ and the number 18 farmers. This could be due to the fact that the majority of respondents who do not watch TV programs do not meet their cognitive needs as in seminars and field days.

\section{The second aim}

The results in Tables 4 show that the highest numerical value of rice farmers' awareness of compost production reached 16 degrees and the lowest numerical value is 5 degrees on a scale amounted to (0-17) degrees with an average of (10.72) degrees and a Standard deviation amounted to (2.30) degrees. According to their degrees of consciousness to three levels (low, medium, high) Table.4

Table 4. Distribution of respondents according to their level of awareness of compost manufacturing

\begin{tabular}{|cccccc|}
\hline Classes & Degree Classe & Number & $\%$ & Arithmetic mean & Notes \\
\hline Low & $5-8$ & 15 & 19.73 & 6.8 & Sd= 2.30 \\
Medium & $9-12$ & 45 & $\mathbf{5 9 . 2 1}$ & 11.2 & Mean=10.72 \\
High & $13-16$ & 16 & $\mathbf{2 1 . 0 5}$ & $\mathbf{1 3 . 0 6}$ & N=76 \\
\hline
\end{tabular}


The Table 4 shows that less than half of the respondents were the level of awareness of compost manufacturing in the middle category $(45 \%)$ with average 59.21. This means that the level of awareness of respondents to compost manufacturing is described as the average inclined to reduces, This colud be due to the lack of interest and the role of extension staff in educating rice farmers about the importance of compost manufacturing. In addition, the reduces provide farmers with the necessary information and knowledge to enable them to benefit from compost, preserve the environment from pollution and maintain soil from degradation..

\section{The third aim}

The results in Tables 5 show that the respondents' answers to the problems that faced by rice farmers in compost manufacturing obtained the weighted mean between 1.98 - 1.69 degrees and a percentage weight between 66 - 56.33\% degrees.

Table 5. problems facing rice farmers when compost manufacturing

\begin{tabular}{|c|c|c|c|c|}
\hline $\begin{array}{l}\text { The sequence } \\
\text { according to the } \\
\text { importance }\end{array}$ & $\begin{array}{l}\text { The sequence } \\
\text { according to } \\
\text { form }\end{array}$ & Problems & $\begin{array}{c}\text { Weight } \\
\text { Percentage }\end{array}$ & $\begin{array}{c}\text { The } \\
\text { Weighted } \\
\text { Average }\end{array}$ \\
\hline 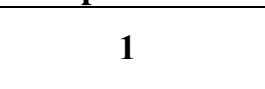 & 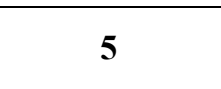 & $\begin{array}{l}\text { The absence of workers trained to } \\
\text { manufacture compost or high wages }\end{array}$ & 66 & 1.98 \\
\hline 2 & 1 & $\begin{array}{l}\text { Lack of awareness of rice farmers in } \\
\text { dealing with agricultural waste }\end{array}$ & 64.66 & 1.94 \\
\hline 3 & 6 & $\begin{array}{c}\text { Lack of excess spaces to manufacture } \\
\text { compost }\end{array}$ & 64.33 & 1.93 \\
\hline 4 & 4 & $\begin{array}{l}\text { Lack of physical resources such as tools } \\
\text { and equipment to cut the mixture of } \\
\text { compost }\end{array}$ & 62.66 & 1.88 \\
\hline 5 & 7 & $\begin{array}{l}\text { Increase the prices of the necessary } \\
\text { supplies }\end{array}$ & 62 & 1.86 \\
\hline 6 & 2 & $\begin{array}{c}\text { Weak guidance role with the necessary } \\
\text { training }\end{array}$ & 58.33 & 1.75 \\
\hline 7 & 3 & $\begin{array}{l}\text { Lack of technical information related to } \\
\text { compost manufacturing }\end{array}$ & 56.33 & 1.69 \\
\hline
\end{tabular}

The Tables 5 shows that the problems facing rice farmers with compost manufacturing have been convergent the weighted mean, However, the problem of "the absence of manpower trained in compost manufacturing or high wages" on the first rank and this confirmed by more than thirds of the respondents. Having obtained a weighted average of 1.98 degrees and a percentage weight of $66 \%$, which is higher than the weighted mean for other problems, The reason colud be due to the lack of specialized training courses necessary to prepare and provide workers with the knowledge and information necessary to compost manufacture. Less than one third of rice farmers' responses focused on the lack of technical information on compost manufacturing". What confirms this is that the problem is ranked last, as it achieved the Weighted Mean average amounted to(1.69) degree and percentage weight of $(56.33 \%)$ degree, which is less than the Weighted Mean of the other paragraphs, This could be due to the weak agricultural extension role in the development, modernization and supply of rice farmers with information on the compost manufacture, as well as the lack of capabilities and modern means and means to provide farmers with that information. It conclude from the above that the extension seminars are one of the most used extension activities by the agricultural guide in the delivery and transfer of agricultural information to rice farmers in the field of compost manufacturing ,The role of agricultural extension in raising the awareness of rice farmers of compost manufacturing average tends to decline which is described as weak, , In addition, there is an absence of working hands in the field of compost manufacturing of rice residues, thus, the researcher recommends the need to pay adequate attention to rice as a strategic crop by utilizing its residues and eliminating the environmental pollution resulting from the burning of these residues and the need to adopt extension activities in a way that is compatible with the rapid changes in society. My thanks and appreciation to the extension training center in the diwaniyah agriculture directorate for their help in the success of the research. 


\section{REFERENCES}

1. Abdul Hafeez, A. and M. Hussein. 2000. The Methods of Scientific Research and Statistical Analysis in the Educational. Psychological and Sports Fields. Book Publishing Center. Cairo. :pp:210

2. Al- Guendhilji, A. I .1991. Scientific Research and the Use of Sources of Information, Dar General of Cultural Affairs. Baghdad presses. Pp:17

3. AL-Jabri, K.R.2011. Search "in Education and Science Curricula Self" st, College of Basic Education. Al-Mustansiriya University. Baghdad.pp:25

4. Al-Ansari, M. B. 2000. The Personal Measure. Modern Books. Egypt. pp:97

5. Al-Bayati,A.T.2008.Statistics and Applications in Educational and Psychological Sciences. University Library. enrichedfor Publishing and Distribution. Amman. Jordan. pp:45

6. Al-Karadi,M.2001.The Social Cost of Environmental Pollution in Egypt. Studies on Environmental Pollution. National Center for Social Research. pp:23

7. Allam, A. S .2002. Study of the educational needs of Rural Women in the governorate of Menoufia, M.Sc. Thesis. Dept. of Agri. Exten. Coll. of Agric. Univ. of Menoufia. pp:75

8. Al-Mughrabi,M. K. 2002. Methods of Scientific Research, the House of Culture for Publishing and Distribution, Amman, Jordan.pp. 25

9. Al-Qawasmi, W .2006. Composting from Organic Waste. National Center for Agricultural Research and Technology Transfer. Extension Bulletin. Jordan.pp:16 10. Al-Salhi, A.T.HD .2016. Communication sources used by the agricultural guide to transfer agricultural information for rice of marshes in the Alabbasia / Najaf AL-Ashraf Governorate, The Iraqi Journal of Agricultural Sciences.47 (3).pp:766

11. AL-Salhi, A. T. H. 2016. Communication activities of the extension workers and their relationship with the application of the wheat crop growers of agricultural recommendations in the province of kirkuk. the Iraqi Journal of Agriculture Sciences.47 (1).pp:352

12. Al-Sarraf, Q. A. 2002. Measurement and Evaluation in Education, National Library of modern publishing, Alexandria.pp:199
13. Altaie,H.K.2004. The Productivity Gap in The Transfer of Agricultural Technology Process, the Iraqi Journal of Agriculture , the 2nd issue,pp:3

14. AlTnobi,M.O.2001.ContactTheory, $1^{\text {th }}$ .Library and Technical Press radiation,. Alexandria. PP:37

15. Bendari, S. I .2006. Environmental Extension for Rural Women in the Field of Treating Solid Waste and Farm Waste in Sharkia Governorate, Ph.D.Coll. of Agriculture. Unive of Ain Shams.pp:82

16. Esmat, M. H. and A. Marwa.2013.The Possibilities of Establishing Units for Mustafa and Others. Agricultural Residues in Some governorates of Egypt. Ministry of Agriculture and Land Reclamation. Extension and Rural Development Research Institute.pp:35

17. Essawi, G .I .1990. A Study of Some Variables Affecting the Environmental Knowledge of Agricultural Extension Workers in the Field of Reducing Pollution of the Rural Environment, M.Sc Thesis. Dept. of Agri. Exten. Coll of Agric Univ. of Tanta.pp:21

18. Ghannam, A .2014. Map of Agricultural Waste, Al-Ahram newspaper, 1 st.edu, Cairo,pp:3

19. Idris, Th. A .2001. The Entrance to Talk in Public Administration, $\mathrm{p}$ 1, University House Publishing, Cairo, pp:17

20. Mohamed, Z .A .2000. A Comparative Study of Dealing with Farm and Non - Farm Wastes in Rural Women, Extension and Rural Development Research Institute, Agricultural Research Center, Research Bulletin, Giza.pp:45

21. Murad, S. A. 2002. Tests and Standards in The Psychological and Educational Science and Preparation Steps, Dar Modern Books for Printing and Publishing, Kuwait,pp:102

22. Mustafa, M. H, and M. Omaima.2010. Agricultural Residues, Ministry of State for Environmental Affairs, Egypt.pp:65

23. Saleh, S .M, Suhair. and M. A. Imam. 2012. knowledge and trends of the wives of farmers towards dealing with agricultural waste in the village of Kom Beheira, Alexandria Journal of Scientific Exchange, $1: 34$ 